\title{
Facile Synthesis of $\mathrm{SnO}_{2}$ Aerogel/Reduced Graphene Oxide Nanocomposites via in Situ Annealing for the Photocatalytic Degradation of Methyl Orange
}

\author{
Taehee Kim ${ }^{1}$, Vinayak G. Parale ${ }^{1}$, Hae-Noo-Ree Jung ${ }^{1}$, Younghun Kim ${ }^{1}$, Zied Driss ${ }^{2}$, \\ Dorra Driss ${ }^{3}$, Abdallah Bouabidi ${ }^{2}$, Souhir Euchy ${ }^{2}$ and Hyung-Ho Park $1, *$ (D) \\ 1 Department of Materials Science and Engineering, Yonsei University, Seoul 03722, Korea; \\ taehee-kim@yonsei.ac.kr (T.K.); vinayakparale3@gmail.com (V.G.P.); nuri_j@yonsei.ac.kr (H.-N.-R.J.); \\ younghun_kim@yonsei.ac.kr (Y.K.) \\ 2 Laboratory of Electromechanical Systems (LASEM), National School of Engineers of Sfax (ENIS), \\ University of Sfax, PO Box 1173, Route Soukra km 3.5, 3038 Sfax, Tunisia; zied.driss@enis.tn (Z.D.); \\ bouabidi_abdallah@yahoo.fr (A.B.); echi.souhir@yahoo.com (S.E.) \\ 3 Laboratory of Molecular and Cellular Screening Processes, Centre of Biotechnology of Sfax (CBS), \\ University of Sfax, PO Box 1177, Road Sidi Mansour km 6, 3018 Sfax, Tunisia; dorra_driss@yahoo.fr \\ * Correspondence: hhpark@yonsei.ac.kr; Tel.: +82-2-2123-2853
}

Received: 31 January 2019; Accepted: 27 February 2019; Published: 4 March 2019

\begin{abstract}
SnO}_{2}$ aerogel/reduced graphene oxide (rGO) nanocomposites were synthesized using the sol-gel method. A homogeneous dispersion of graphene oxide (GO) flakes in a tin precursor solution was captured in a three-dimensional network $\mathrm{SnO}_{2}$ aerogel matrix and successively underwent supercritical alcohol drying followed by the in situ thermal reduction of GO, resulting in $\mathrm{SnO}_{2}$ aerogel/rGO nanocomposites. The chemical interaction between aerogel matrix and GO functional groups was confirmed by a peak shift in the Fourier transform infrared spectra and a change in the optical bandgap of the diffuse reflectance spectra. The role of rGO in 3D aerogel structure was studied in terms of photocatalytic activity with detailed mechanism of the enhancement such as electron transfer between the $\mathrm{GO}$ and $\mathrm{SnO}_{2}$. In addition, the photocatalytic activity of these nanocomposites in the methyl orange degradation varied depending on the amount of rGO loading in the $\mathrm{SnO}_{2}$ aerogel matrix; an appropriate amount of rGO was required for the highest enhancement in the photocatalytic activity of the $\mathrm{SnO}_{2}$ aerogel. The proposed nanocomposites could be a useful solution against water pollutants.
\end{abstract}

Keywords: $\mathrm{SnO}_{2}$ aerogel; sol-gel method; graphene oxide; nanocomposite; photocatalysis

\section{Introduction}

The demand for solutions against several environmental issues has recently increased; in particular, the presence of air pollutants and organic dyes in water are global concerns. Since the latters are often highly toxic and have mutagenic properties, their removal is a major problem in the industry [1-3]. Until now, many efforts have been made to decompose the organic pollutants by using various processes involving, e.g., (homogeneous and/or heterogeneous) catalysts, adsorbents, and ozone [4-8] and photocatalysis is one of the most effective and economical paths for their removal [9-13]. Semiconducting metal oxides such as $\mathrm{TiO}_{2}, \mathrm{ZnO}$, and $\mathrm{SnO}_{2}$ have been widely used as photocatalysts due to their ability to generate electron-hole pairs when photon energy is provided [12-19]. Among them, $\mathrm{SnO}_{2}$ has gained much attention because of its high natural abundance, optical transparency, and physicochemical stability, relatively high electrical conductivity, and lack of toxicity [20-22]. $\mathrm{SnO}_{2}$ is an n-type semiconductor with a wide bandgap $(3.6 \mathrm{eV})$ and a 
rutile-type crystal structure, but it exhibits a low photocatalytic activity due to such wide bandgap and its high photogenerated electron-hole pair recombination rate [23]. Also, the economic aspects of the preparation of $\mathrm{SnO}_{2}$ photocatalyst for the mass production is still challenging. The cost and compatibility should be considered in photocatalytic degradation [24-28].

Many previous studies aimed to enhance the photocatalytic activity of $\mathrm{SnO}_{2}$-based semiconductors by introducing nanostructures and composites [29-33]. Different nanostructures for $\mathrm{SnO}_{2}$-based photocatalysts, such as nanoparticles [29], flower-like structures [30], and simonkolleite nanopetals [31], have been reported so far. In addition, the use of $\mathrm{SnO}_{2}$ composites with carbon materials (in particular, carbon core-shell particles [34], graphene oxide (GO) [35], activated carbon [36], and fullerene [37]) instead of pure $\mathrm{SnO}_{2}$ to decrease the electron-hole recombination rate, which would enhance the photocatalytic activity, has been investigated. Moreover, some studies have reported chemical interactions between these carbon materials and the $\mathrm{SnO}_{2}$ matrix, which decrease the bandgap and improve the photocatalytic activity $[38,39]$.

In the present work, we synthesized porous $\mathrm{SnO}_{2}$ aerogel/reduced $\mathrm{GO}(\mathrm{rGO})$ nanocomposites via an epoxide-assisted sol-gel process. GO flakes were uniformly dispersed in a tin solution and captured in a colloidal $\mathrm{SnO}_{2}$ three-dimensional (3D) network. Then, the in situ thermal reduction of GO was performed continuously in autoclave during the supercritical drying of the resulting nanocomposites. To the best of our knowledge, this is the first report on the in situ annealing of $\mathrm{SnO}_{2}$ aerogel/GO nanocomposites in an autoclave, providing $\mathrm{SnO}_{2}$ aerogel/rGO nanocomposites as the final product. Furthermore, the dispersion of 2D GO sheets would hinder the network formation. In this study, the reaction condition was carefully controlled to achieve the uniform distribution as well as the reaction between oxygen containing functional groups on GO sheet and Sn metal center and confirmed by various characterizations. In addition, the synthesized nanocomposites were analyzed in detail and their performance in the photocatalytic degradation of methyl orange (MO) was quantified. As per our knowledge, $\mathrm{SnO}_{2}$ aerogel and $\mathrm{rGO}$ composite has not been studied in application of photocatalysis.

\section{Materials and Methods}

\subsection{Sample Preparation}

Tin tetrachloride pentahydrate $\left(\mathrm{SnCl}_{4} \cdot 5 \mathrm{H}_{2} \mathrm{O}\right)$ was added to a mixture of water and ethanol (3:1, $\mathrm{v} / \mathrm{v}$ ) and stirred for $1 \mathrm{~h}$; after complete dissolution, $0.05,0.1$, and $0.3 \mathrm{wt} . \%$ of GO flakes were added to each solution separately and their uniform distribution was ensured via ultrasonic processing for $1 \mathrm{~h}$. When the GO flakes were suspended in the tin salt solution, this was chilled in an ice bath. Excess propylene oxide $\left(\mathrm{C}_{3} \mathrm{H}_{6} \mathrm{O}, 143 \mathrm{mmol}\right.$; Sigma-Aldrich, St. Louis, MO, USA) was added to the solution dropwise by using a syringe. The chemistry of the epoxide-initiated gelation method is well described in [40]; the gelation took place in $10 \mathrm{~min}$ and the alcogel was left for $20 \mathrm{~min}$ to complete the reaction. The resulting alcogel was added with ethanol and aged at room temperature for 3 days by exchanging with fresh ethanol every $24 \mathrm{~h}$. Then, the solvent exchange was performed with methanol for $24 \mathrm{~h}$. The so-obtained $\mathrm{SnO}_{2}$ alcogel underwent supercritical methanol drying at $265^{\circ} \mathrm{C}$ and 105 bar in an autoclave equipped with a $2 \mathrm{~L}$ vessel (Parr Instruments, Moline, IL, USA). After complete supercritical fluid extraction, in situ drying was performed in the same autoclave by heating the vessel to $300^{\circ} \mathrm{C}$ under $\mathrm{N}_{2}$ flow and the dried aerogel was annealed for $1 \mathrm{~h}$ to induce the reduction of GO to rGO.

\subsection{Characterization}

A Fourier transform infrared spectroscopy (FTIR) system (Perkin Elmer, Waltham, MA, USA) was used to monitor the reaction and characterize the impurities. The specific surface area of nanoporous aerogel composites was measured using a Brunauer-Emmett-Teller (BET) analyzer (Quantachrome, Boynton Beach, FL, USA) and the Barrett-Joyner-Halenda (BJH) method. Their crystallinity and structure were investigated with an X-ray diffraction (XRD) system (Rigaku Ultima, Tokyo, Japan) using $\mathrm{Cu} \mathrm{K} \alpha$ radiation $(1.5418 \AA)$ in the $20-80^{\circ} 2 \theta$ range. The surface morphology of the $\mathrm{SnO}_{2}$ 
aerogel/rGO nanocomposites was analyzed using a field emission scanning electron microscopy (FESEM) system (JEOL JSM 7001F, Tokyo, Japan). The photoluminescence (PL) analysis was performed on a LabRam Aramis system (Horriba Jobin Yvon, Madrid, Spain) at room temperature and with a laser excitation wavelength of $\sim 325 \mathrm{~nm}$. Ultraviolet diffuse reflectance spectra (UV-DRS) were recorded on a spectrometer (JASCO 780, Tokyo, Japan) was performed using powder DRS kit at room temperature.

\subsection{Photocatalyst Properties}

The photocatalytic activity of both pristine $\mathrm{SnO}_{2}$ aerogel and $\mathrm{SnO}_{2}$ aerogel/rGO nanocomposites was determined based on the degradation degree of an aqueous MO dye solution. The photocatalytic decolorization of the MO solution was derived from its absorption (absorption peak at $464 \mathrm{~nm}$ by using a UV-visible (Vis) spectrophotometer (JASCO 570, Tokyo, Japan) in the 300-800 nm range. The initial concentration of the MO dye in the solution was $1 \times 10^{-5} \mathrm{M}$ and the photocatalyst ( $1 \mathrm{mg} \mathrm{mL}^{-1}$ ) was dispersed in it. The photocatalytic degradation was performed using a UV lamp ( $40 \mathrm{~W}$; Philips TL-K) with peak intensity at $370 \mathrm{~nm}$ irradiating directly the solution after achieving the adsorption/desorption equilibrium for $30 \mathrm{~min}$. The solution was stirred continuously with a magnetic stirrer. After centrifugation with a microcentrifuge (DAIHAN CF-10, Seoul, Korea), the absorbance spectra of the solution with the photocatalyst suspension (approximately $1.2 \mathrm{~mL}$ aliquots) were recorded over time at ambient conditions.

\section{Results and Discussion}

Metal alkoxides are generally used as non-silica-based precursors in the synthesis of aerogels [41-43], but they are costly and their reactivity is hard to control [44]. In this study, cost effective tin chloride was selected as the precursor and propylene oxide was used to initialize the sol-gel process for the synthesis of the $\mathrm{SnO}_{2}$ aerogel/rGO nanocomposites. Propylene oxide acts as proton scavenger and ring-strained epoxide, increasing the hydrolysis and condensation rate [45]; its addition usually speeds up the gelation (less than a minute), leading to the formation of an opaque white alcogel $[40,46]$. However, in this study, the tin precursor solution and propylene oxide were chilled in an ice bath to obtain uniform pores in the $\mathrm{SnO}_{2}$ aerogel, giving a clear transparent alcogel. In addition, due to the relatively fast gelation (approximately $10 \mathrm{~min}$ ), the GO flakes homogeneously dispersed via ultrasonication were trapped within the $\mathrm{SnO}_{2}$ matrix without large agglomerations. The porous $\mathrm{SnO}_{2}$ aerogel/rGO nanocomposites were obtained by removing the solvent in the 3D wet gel via drying at supercritical pressure and temperature. The thermal annealing method was used to reduce $\mathrm{GO}$ to $\mathrm{rGO}$ by decomposing the oxygen-containing functional groups. The BET and XRD results about the textural and crystalline properties of the as-synthesized pristine $\mathrm{SnO}_{2}$ aerogel (PTO) and $\mathrm{SnO}_{2}$ aerogel/rGO nanocomposites (named as TGO05, TGO1, and TGO3 according to the rGO loading of $0.05,0.1$, and $0.3 \mathrm{wt} . \%$, respectively) are shown in Figure 1 and Table 1.

(a)

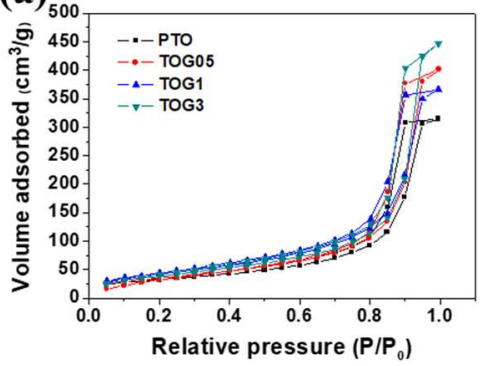

(b)

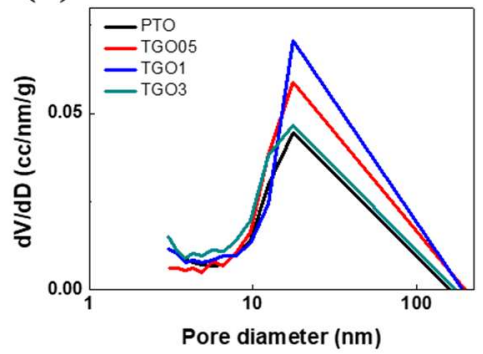

(c)

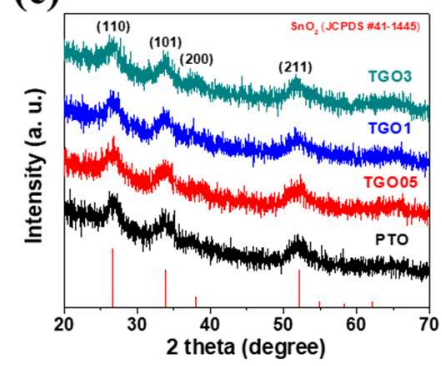

Figure 1. (a) Brunauer-Emmett-Teller isotherms, (b) Barrett-Joyner-Halenda graph and (c) X-ray diffraction spectra of pristine $\mathrm{SnO}_{2}$ aerogel (PTO) and $\mathrm{SnO}_{2}$ aerogel/reduced graphene oxide (rGO) nanocomposites with different rGO loadings (0.05 wt.\%: TGO05; 0.1 wt.\%: TGO1; 0.3 wt.\%: TGO3). 
The nanoporous structure of the various samples was determined via the BET analysis (Figure 1a). All isotherms showed type $\mathrm{V}$ according to the IUPAC classification, revealing the mesoporous structure of the $\mathrm{SnO}_{2}$ aerogel. PTO exhibited a slightly smaller surface area compared to the rGO-added nanocomposites, while TGO3 showed the largest one $\left(157 \mathrm{~m}^{2} \mathrm{~g}^{-1}\right)$; the specific surface area of the $\mathrm{SnO}_{2}$ aerogel increased with the rGO loading. The rGO presence could clearly enhance this parameter without hindering the colloidal aerogel formation and this was due to the high initial surface area of the GO flakes. Moreover, the well-distributed rGO sheets with a high mechanical strength could reduce the thermal stress induced during the thermal annealing step. Moreover, the average pore volumes and pore sizes, calculated via the $\mathrm{BJH}$ method (Figure 1b), slightly increased in the $\mathrm{SnO}_{2}$ aerogel/rGO nanocomposites compared to the pristine sample.

Figure 1c shows the XRD patterns of the $\mathrm{SnO}_{2}$ aerogel/rGO nanocomposite after the heat treatment. The $\mathrm{SnO}_{2}$ aerogel exhibited a rutile-type tetragonal crystal structure and the XRD peaks at $26.61^{\circ}, 33.89^{\circ}, 37.95^{\circ}$, and $51.78^{\circ}$ corresponded to the (110), (101), (200), and (211) crystal planes of the $\mathrm{SnO}_{2}$ aerogel/rGO nanocomposites, respectively, with the following cell parameters: $\mathrm{a}, \mathrm{b}=4.738 \AA$ and c = 3.187 $\AA$ (JCPDS \#41-1445) [47]. However, the graphene diffraction pattern could not be indexed because of the low amount of GO flakes. The average crystallite size of the aerogel nanocomposites, calculated using the Scherrer equation, was approximately $3.4 \mathrm{~nm}$ for all the samples and no distinctive influence of the rGO addition was observed on the crystallinity of the $\mathrm{SnO}_{2}$ aerogel.

Table 1. Textural properties and crystallite size of pristine $\mathrm{SnO}_{2}$ aerogel and $\mathrm{SnO}_{2}$ aerogel/reduced graphene oxide (rGO) nanocomposites with different rGO loadings.

\begin{tabular}{ccccc}
\hline $\begin{array}{c}\text { Graphene Content } \\
(\mathbf{w t .} \%)\end{array}$ & $\begin{array}{c}\text { Surface Area } \\
\left(\mathbf{m}^{\mathbf{2}} \mathbf{g}^{-\mathbf{1}} \mathbf{)}\right.\end{array}$ & $\begin{array}{c}\text { Pore Volume } \\
\left(\mathbf{c m}^{\mathbf{3}} \mathbf{g}^{\mathbf{- 1}}\right)\end{array}$ & $\begin{array}{c}\text { Pore diameter } \\
(\mathbf{n m})\end{array}$ & $\begin{array}{c}\text { Average Crystallite } \\
\text { Size } \mathbf{( n m})\end{array}$ \\
\hline 0 & 117 & 0.49 & 17 & 3.48 \\
0.05 & 131 & 0.62 & 19 & 3.42 \\
0.1 & 147 & 0.69 & 18 & 3.46 \\
0.3 & 157 & 0.57 & 15 & 3.35 \\
\hline
\end{tabular}

Exfoliated GO can be reduced to rGO via simple annealing under oxidizing or inert atmosphere [48], but annealing $\mathrm{SnO}_{2}$ aerogel/GO composites under air atmosphere would reduce the number of oxygen vacancies in the aerogel, lowering its photocatalytic activity. Therefore, after drying, the reaction vessel was heated to $300{ }^{\circ} \mathrm{C}$ to induce the reduction of the GO flakes [48]; this is a facile method for in situ thermal annealing with desirable atmosphere consecutively just after the supercritical alcohol drying. For comparison, the BET specific surface areas of PTO and the various $\mathrm{SnO}_{2}$ aerogel/rGO nanocomposites were measured before, during, and after (i.e., after the supercritical drying) the in situ annealing (Table 2). The results suggested that the in situ annealing method can minimize the thermal stress. Therefore, the $\mathrm{GO}$ reduction in the $\mathrm{SnO}_{2}$ aerogel matrix via in situ annealing could introduce the enhancement of the specific surface area.

Table 2. Comparison of the effect of in situ annealing on the specific surface area of $\mathrm{SnO}_{2}$ aerogel, with and without the addition of graphene oxide.

\begin{tabular}{cccc}
\hline $\begin{array}{c}\text { Graphene Content } \\
(\mathbf{w t .} \%)\end{array}$ & $\begin{array}{c}\text { Surface Area } \\
\left(\mathbf{m}^{\mathbf{2}} \mathbf{~} \mathbf{- 1}\right) \\
\text { Before Annealing }\end{array}$ & $\begin{array}{c}\text { Surface Area } \\
\left(\mathbf{m}^{\mathbf{2}} \mathbf{g}^{-\mathbf{1}} \mathbf{)}\right.\end{array}$ & $\begin{array}{c}\text { Surface Area } \\
\left(\mathbf{m}^{\mathbf{2}} \mathbf{~}^{-\mathbf{1}} \mathbf{)}\right. \\
\text { Post Annealing }\end{array}$ \\
\hline 0 & 199 & 117 & 84 \\
0.05 & 277 & 131 & 75 \\
0.1 & 314 & 147 & 73 \\
0.3 & 359 & 157 & 92 \\
\hline
\end{tabular}

Figure 2 shows the FTIR spectra of PTO and the various $\mathrm{SnO}_{2}$ aerogel/rGO nanocomposites. All samples show weak and broad absorption peaks of hydroxyl $(-\mathrm{OH})$ group around $3400 \mathrm{~cm}^{-1}$ 
owing to the surface hydroxyl groups on the $\mathrm{SnO}_{2}$ aerogel primary particles. This represents the hydrophilic surface which would favor to absorb aqueous solution for photocatalytic organic dye degradation [49]. In addition, Figure 2a shows a broad absorption peak at around $495 \mathrm{~cm}^{-1}$, for all samples, that indicates the formation of $\mathrm{Sn}-\mathrm{O}-\mathrm{Sn}$ bonds via the epoxide-initiated sol-gel process. However, this peak shifted toward higher wavenumbers with increasing the GO content, as shown in the magnified spectra in Figure $2 b$. This broad peak was probably a combination of Sn-O-Sn vibration and Sn-O-C stretching vibration $\left(520 \mathrm{~cm}^{-1}\right)[50,51]$. The presence of the latter confirmed the chemical bond formation between $\mathrm{SnO}_{2}$ aerogel and residual oxygen-containing functional groups in GO during the synthesis.
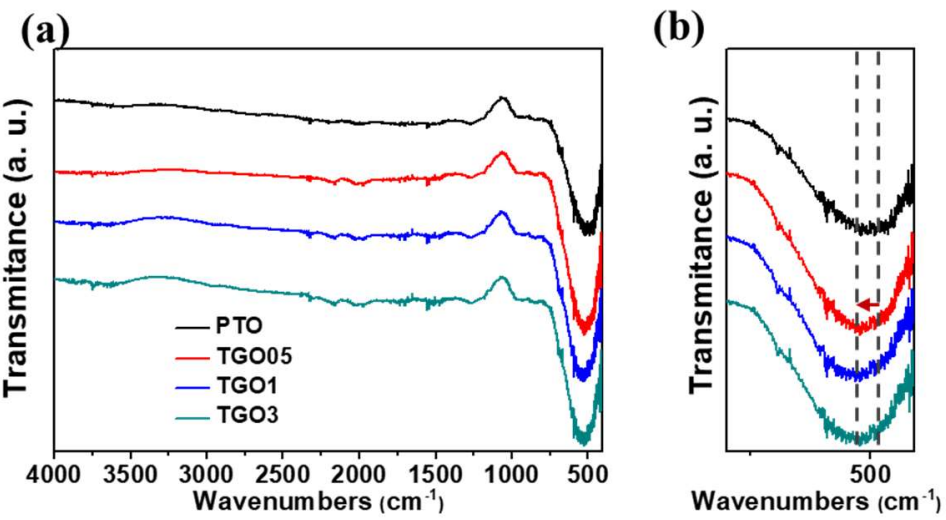

Figure 2. (a) Fourier transform infrared spectra and (b) their magnification in the low-wavenumber region for the pristine $\mathrm{SnO}_{2}$ aerogel (PTO) and the $\mathrm{SnO}_{2}$ aerogel/reduced graphene oxide (rGO) nanocomposites with different rGO loadings (0.05 wt.\%: TGO05; 0.1 wt.\%: TGO1; 0.3 wt.\%: TGO3).

PL emission is an important tool to determine the charge transportation and separation of electron-hole pairs. Figure 3 shows the photoluminescence spectra of PTO and the various $\mathrm{SnO}_{2}$ aerogel/rGO nanocomposites, measured at $325 \mathrm{~nm}$. PTO exhibited a strong emission at around 554 nm due to the crystal defect of the $\mathrm{SnO}_{2}$ matrix [52], which significantly decreased in TGO05, TGO1, and TGO3; however, these samples showed similar intensities regardless the rGO amount added. This phenomenon indicated that the rGO addition could inhibit the electron-hole pair recombination, which implied that the rGO-based nanocomposites acted as electron trapping sites, benefiting the charge transfer in the enhanced photocatalytic activity. In addition, the PL quenching effect was also caused by the excellent electrical conductivity of rGO which will favor the photocatalytic activity [23].

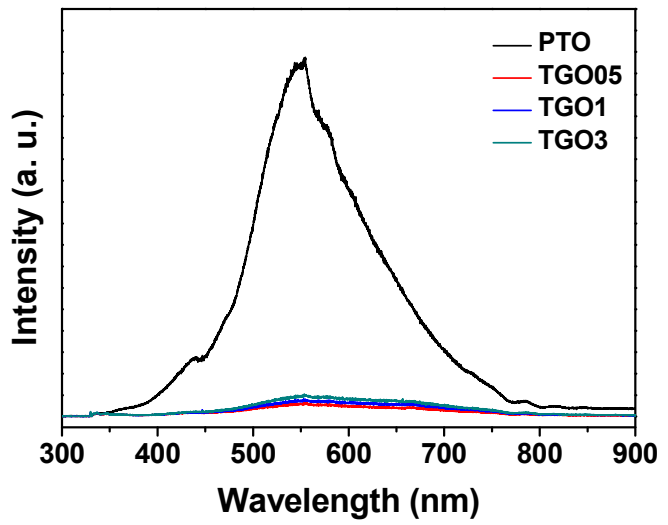

Figure 3. Photoluminescence spectra of pristine $\mathrm{SnO}_{2}$ aerogel (PTO) and $\mathrm{SnO}_{2}$ aerogel/reduced graphene oxide (rGO) nanocomposites with different rGO loadings (0.05 wt.\%: TGO05; 0.1 wt.\%: TGO1; 0.3 wt.\%: TGO3). 
The FESEM images of PTO and TGO1 are shown in Figure 4. In regards to the various rGO-added samples, only the results for TGO1 are presented because they all exhibited similar surface morphologies but more rGO graphene incorporation sites are found. The increase in the rGO loading did not influence the surface morphology of the nanocomposites. The colloidal porous nature of PTO was confirmed by a mesoporous aerogel network (Figure $4 a$ ). Figure $4 \mathrm{~d}$ confirms the incorporation of rGO in the $\mathrm{SnO}_{2}$ matrix, which clearly depicts the growth of primary particles of aerogel on the surface of rGO. The visible well deposition of the aerogel particles allowed us to assume that there was a chemical interaction between the aerogel matrix and the functional groups on the rGO surface.
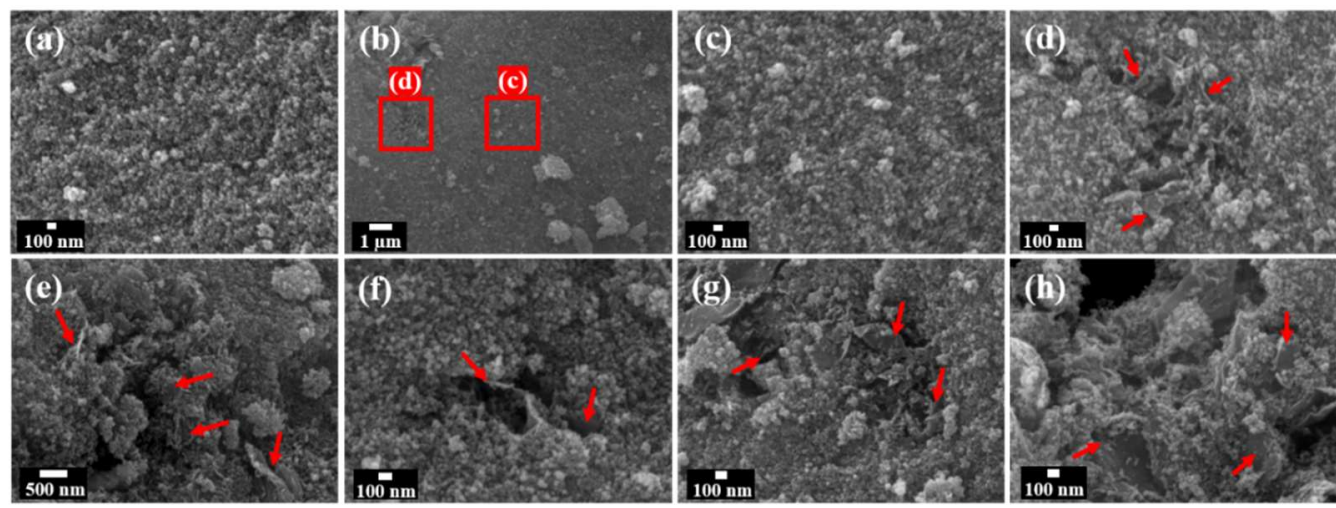

Figure 4. Field-emission scanning electron microscopy images of: (a) pristine $\mathrm{SnO}_{2}$ aerogel (PTO); (b) $\mathrm{SnO}_{2}$ aerogel/reduced graphene oxide (rGO) nanocomposites with an rGO loading of 0.1 wt.\% (TGO1); (c,d) magnification of red square areas in (b), showing the rGO incorporation in the $\mathrm{SnO}_{2}$ aerogel matrix; (e-h). The red arrows represent rGO sheets.

The chemical bond formation between $\mathrm{SnO}_{2}$ matrix and the functional groups on $\mathrm{GO}$ was further confirmed by the UV-DRS analysis. Figure 5a shows the DRS spectra of PTO and TGO1 samples, revealing a considerable difference after the GO addition. Figure $5 b$ shows their Kubelka-Munk plots; the calculated optical bandgaps of the semiconductor powders were approximately 3.56 and $3.29 \mathrm{eV}$ for PTO and TGO1, respectively. The bandgap of PTO well agreed with the value for $\mathrm{SnO}_{2}$ nanoparticles reported in literature [53]. The rGO incorporation corresponded to a narrower bandgap, which could be attributed to the $\mathrm{Sn}-\mathrm{O}-\mathrm{C}$ bond formation between $\mathrm{SnO}_{2}$ and the rGO functional groups [50]. Since new impurity energy levels above the valence-band edge would be generated by the rGO introduction, a smaller input energy would be required for the charge carrier excitation. Therefore, the $\mathrm{SnO}_{2}$ aerogel/rGO nanocomposite exhibited a decrease in the optical bandgap with the $\mathrm{Sn}-\mathrm{O}-\mathrm{C}$ bond formation. Although this phenomenon has been previously observed in the case of $\mathrm{TiO}_{2}$-graphene composites, no such mechanism has been reported for $\mathrm{SnO}_{2}$-reduced graphene composites so far [54].
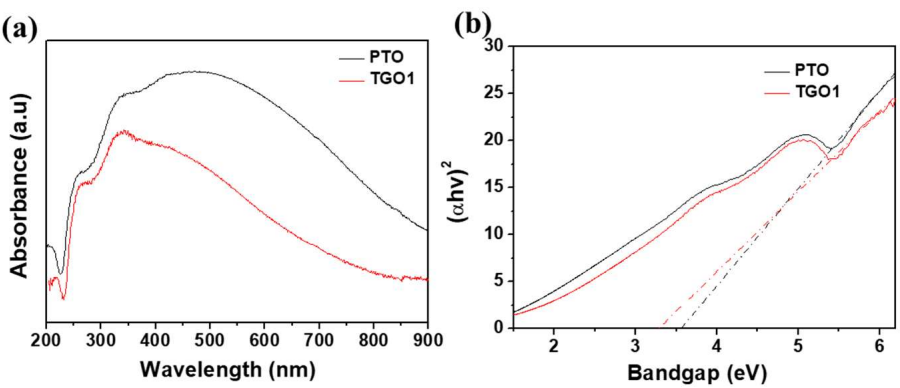

Figure 5. (a) Diffuse reflectance spectra and (b) Kubelka-Munk plots for the calculated bandgaps of pristine $\mathrm{SnO}_{2}$ aerogel (PTO) and $\mathrm{SnO}_{2}$ aerogel/reduced graphene oxide (rGO) nanocomposites with an rGO loading of $0.1 \mathrm{wt} . \%$ (TGO1). 
The photocatalytic activity of both pristine $\mathrm{SnO}_{2}$ aerogel and its $\mathrm{rGO}$ nanocomposites was investigated by the degradation of an $\mathrm{MO}$ solution. The $\mathrm{MO}$ concentration was determined by the absorbance of the solution at $464 \mathrm{~nm}$ using UV-Vis spectrophotometer after the centrifugal separation of the photocatalyst powder. All the MO solutions (with pristine and nanocomposite catalysts) were left in dark for $30 \mathrm{~min}$ to achieve the adsorption/desorption equilibrium state on the photocatalyst surface. Then, the photocatalytic activity of the samples was initiated via UV light irradiation under continuous magnetic stirring. The absorbance of the $\mathrm{MO}$ solution was measured starting from time $\mathrm{t}=0$, every 10 min of irradiation. Figure 6 shows the changes in the concentration ratio $C / C_{0}$, where $C_{0}$ and $C$ are the $\mathrm{MO}$ concentrations at the initial time $t_{0}$ and the irradiation time $t$, respectively, for the various samples. PTO exhibited a moderately reasonable photocatalytic activity, with a 56\% MO degradation after 60 min of UV irradiation. Moreover, the rGO addition resulted in enhanced photocatalytic activity, reaching with TGO1 an 84\% MO degradation in the same time. The activity of TGO05 was also relatively higher compared to PTO, but the difference was negligible. The enhancement in the photocatalytic activity of TGO1 was discussed by a comparison with PTO, confirming that the rGO introduction can considerably enhance the photocatalytic degradation of MO.

Figure $6 \mathrm{~b}$ shows the photocatalytic reaction rate constant $\mathrm{k}$ values, derived from the slope of the $\ln \left(\mathrm{C}_{0} / \mathrm{C}\right)$ versus time plot, for PTO, TGO05, TGO1, and TGO3. All samples exhibited a first-order rate law with a linear behavior. The highest $\left(2.9 \times 10^{-2} \mathrm{~min}^{-1}\right)$ and lowest $\left(1.2 \times 10^{-2} \mathrm{~min}^{-1}\right) \mathrm{k}$ values were observed with TGO1 and PTO, respectively, meaning that TGO1 attained a 2.4-fold higher photocatalytic degradation rate compared to PTO.

(a)

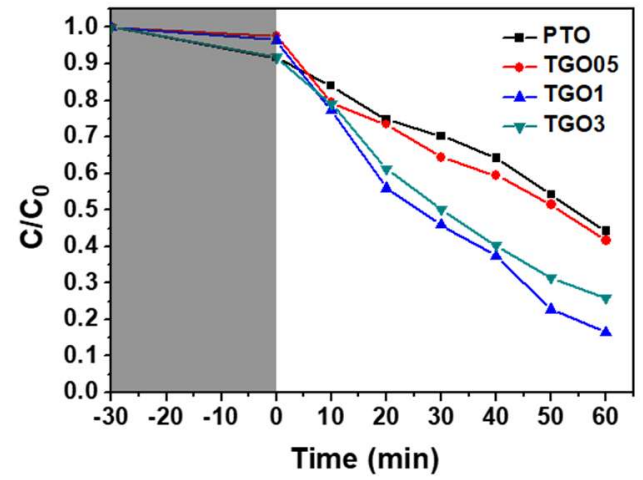

(b)

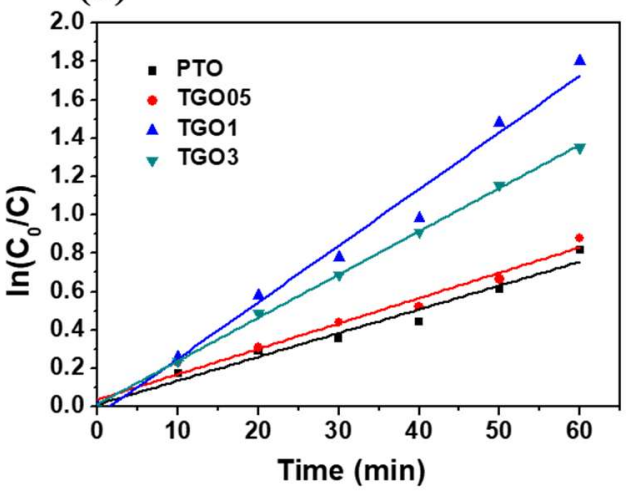

Figure 6. Photocatalytic activities of pristine $\mathrm{SnO}_{2}$ aerogel (PTO) and $\mathrm{SnO}_{2}$ aerogel/reduced graphene oxide (rGO) nanocomposites with different rGO loadings (0.05 wt.\%: TGO05; 0.1 wt.\%: TGO1; 0.3 wt.\%: TGO3), represented as (a) the degradation of methyl orange $(\mathrm{MO})$ dye (in terms of concentration ratio $\mathrm{C} / \mathrm{C}_{0}$, where $\mathrm{C}_{0}$ and $\mathrm{C}$ are the $\mathrm{MO}$ concentrations at initial time $\mathrm{t}_{0}$ and a given ultraviolet irradiation time $t)$ and $(b)$ its reaction rate during time.

In general, the three main factors influencing the photocatalytic activity are the light absorption intensity, the specific surface area, and the separation/recombination rate of photoexcited electron-hole pairs [23]. In this study, the rGO addition to $\mathrm{SnO}_{2}$ sol increased the specific surface area of the final aerogel nanocomposites by introducing more reactive surface sites and, hence, generating more electron-hole pairs [55]. In addition, the photoexcited electrons could move to the conduction band of $\mathrm{rGO}$ to interact with absorbed $\mathrm{O}_{2}$ and generate reactive radicals for the $\mathrm{MO}$ degradation; this phenomenon was hindered by the electron-hole pair recombination, enhancing the photocatalytic activity of the $\mathrm{SnO}_{2}$ aerogel/rGO nanocomposites. The detailed mechanisms for the formation of reactive radical intermediates during the photoactivation of the $\mathrm{SnO}_{2} / \mathrm{rGO}$ nanocomposites are 
described by the Equations (1)-(6) and the illustration in Figure 7. The photogenerated electron could move to $\mathrm{rGO}$ and produce reactive superoxide anions, eventually leading to the MO degradation.

$$
\begin{gathered}
\mathrm{SnO}_{2}+\mathrm{hv} \rightarrow \mathrm{SnO}_{2}\left(\mathrm{e}^{-}+\mathrm{h}^{+}\right) \\
\mathrm{SnO}_{2}\left(\mathrm{e}^{-}+\mathrm{h}^{+}\right)+\mathrm{rGO} \rightarrow \mathrm{SnO}_{2}\left(\mathrm{~h}^{+}\right)+\mathrm{rGO}\left(\mathrm{e}^{-}\right) \\
\mathrm{SnO}_{2}\left(\mathrm{~h}^{+}\right)+\mathrm{H}_{2} \mathrm{O} \rightarrow \mathrm{SnO}_{2}+\mathrm{OH}^{-}+\mathrm{H}^{+} \\
\mathrm{rGO}\left(\mathrm{e}^{-}\right)+\mathrm{O}_{2} \rightarrow \mathrm{rGO}+\mathrm{O}_{2}^{\cdot-} \\
\mathrm{O}_{2}^{\cdot-}+\mathrm{H}_{2} \mathrm{O} \rightarrow \mathrm{H}_{2} \mathrm{O}^{-}+\mathrm{OH}^{-} \\
\mathrm{MO}+\mathrm{OH}^{\cdot} / \mathrm{O}_{2} \cdot-\mathrm{H}_{2} \mathrm{O} \rightarrow \mathrm{CO}_{2}+\mathrm{H}_{2} \mathrm{O}
\end{gathered}
$$

On the other hand, the addition of excess graphene to the $\mathrm{SnO}_{2}$ aerogel matrix (i.e., the TGO3 case) reduced the enhancement of the photocatalytic activity, resulting in a $74 \% \mathrm{MO}$ degradation in $60 \mathrm{~min}$ of UV irradiation. The photocatalytic activity was in the following order: TGO1 > TGO3 > TGO05 > PTO Hence, a suitable amount of rGO loading would benefit the photocatalytic activity while its excess would decrease the photon absorption efficiency by $\mathrm{SnO}_{2}$ [56,57]; furthermore, such enhancement could be possible only at a certain extent. At the beginning state of the study, the experiment was designed to have $0.5-2.0 \mathrm{wt} . \%$ of $\mathrm{rGO}$ in $\mathrm{SnO}_{2}$ aerogel. However, authors have found that large amount of rGO in $\mathrm{SnO}_{2}$ aerogel retarded the photocatalytic activity as well as the surface area. This would happen because an excess rGO loading could increase the probability of collisions between

\begin{tabular}{|c|c|c|c|c|}
\hline Photocatalyst & $\begin{array}{c}\text { Light } \\
\text { Source/Pollutant }\end{array}$ & $\begin{array}{l}\text { Experimental } \\
\text { Condition }\end{array}$ & $\begin{array}{c}\text { Photodegradation } \\
\text { Efficiency }\end{array}$ & Ref. \\
\hline $\begin{array}{l}\mathrm{SnO}_{2} \text { nanoparticles } \\
\text { coated on MWCNT }\end{array}$ & $\begin{array}{l}4 \times 6 \mathrm{~W} \text { fluorescent } \\
\text { halogen lamps }(254 \\
\mathrm{nm}) \text {, methyl orange }\end{array}$ & $\begin{array}{c}\mathrm{C}: 1000 \mathrm{mg} \mathrm{L}^{-1} ; \mathrm{P}: \\
\quad 20 \mathrm{mg} \mathrm{L}^{-1}\end{array}$ & $45 \mathrm{~min} / 94 \%$ & [17] \\
\hline $\begin{array}{c}\text { Simonkolleite } \\
\text { nanopetals with } \\
\mathrm{SnO}_{2}\end{array}$ & $\begin{array}{c}3 \times 8 \mathrm{~W} \text { UV lamps } \\
(254 \mathrm{~nm}), \\
\text { rhodamine } 6 \mathrm{G}\end{array}$ & $\begin{array}{c}\mathrm{C}: 500 \mathrm{mg} \mathrm{L}^{-1} ; \mathrm{P}: \\
\quad 10 \mathrm{mg} \mathrm{L}^{-1}\end{array}$ & $32 \min / 100 \%$ & [25] \\
\hline $\begin{array}{c}\mathrm{SnO}_{2}-\text { graphene } \\
\text { nanocomposite (solid } \\
\text { state) }\end{array}$ & $\begin{array}{l}300 \mathrm{~W} \text { mercury } \\
\text { lamp, methyl orang } \\
\text { and rhodamine B }\end{array}$ & $\begin{array}{l}\mathrm{C}: 500 \mathrm{mg} \mathrm{L}^{-1} ; \mathrm{P}: \\
\quad 20 \mathrm{mg} \mathrm{L}^{-1}\end{array}$ & $\begin{array}{l}\text { Methyl orange } \\
40 \text { min } / 95 \% \\
\text { Rhodamine B } \\
60 \mathrm{~min} / 97 \%\end{array}$ & [49] \\
\hline $\begin{array}{c}\mathrm{SnO}_{2}-\mathrm{CNT} \\
\text { nanocomposites }\end{array}$ & $\begin{array}{l}9 \mathrm{~W} \text { eight UV-vis } \\
\text { lamps }(365 \mathrm{~nm}), \\
\text { methylene blue } \\
\text { and methyl orange }\end{array}$ & $\begin{array}{l}\text { C: } 200 \mathrm{mg} \mathrm{L}^{-1} ; \mathrm{P}: \\
20 \text { ppm (methylene } \\
\text { blue), } 10 \text { ppm } \\
\text { (methyl orange) }\end{array}$ & $\begin{array}{l}\text { Methylene blue } \\
180 \text { min/93\% } \\
\text { Methyl orange } \\
180 \text { min } / 79 \%\end{array}$ & [1] \\
\hline $\begin{array}{c}\mathrm{SnO}_{2} \text { aerogel/rGO } \\
\text { nanocomposite }\end{array}$ & $\begin{array}{c}40 \text { W UV lamp } \\
\text { (370 nm), methyl } \\
\text { orange }\end{array}$ & $\begin{aligned} \mathrm{C}: & 1 \times 10^{-5} \mathrm{M} ; \mathrm{P}: \\
& 100 \mathrm{mg} \mathrm{L}^{-1}\end{aligned}$ & $\begin{array}{l}\text { Methyl orange } \\
60 \mathrm{~min} / 84 \%\end{array}$ & This work \\
\hline
\end{tabular}
photogenerated electrons and holes, favoring the electron-hole pair recombination and, thus affecting the photocatalytic activity [58]. Moreover, $\mathrm{SnO}_{2}$ aerogel/rGO nanocomposites are compared with previous reported $\mathrm{SnO}_{2}$ based photocatalysts in Table 3 .

Table 3. Comparison of photocatalytic performance of $\mathrm{SnO}_{2}$ aerogel/rGO nanocomposite photocatalyst in this work with previously reported composite photocatalysts. 


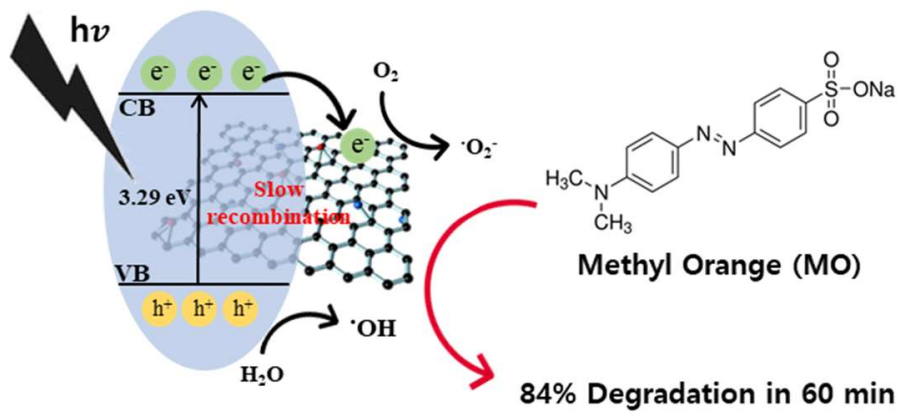

Figure 7. Schematic of $\mathrm{MO}$ dye photodegradation by using $\mathrm{SnO}_{2}$ aerogel/reduced graphene oxide nanocomposites under ultraviolet light.

\section{Conclusions}

We introduced GO into an $\mathrm{SnO}_{2}$ aerogel matrix followed by its reduction to $\mathrm{rGO}$ via a facile in situ annealing process in a supercritical autoclave. During the sol-gel synthesis, the dispersed rGO flakes were captured in the $\mathrm{SnO}_{2}$ matrix and the colloidal $\mathrm{SnO}_{2}$ reacted with their functional groups, as confirmed by the FTIR and UV-DRS spectra. The so-obtained nanocomposites exhibited enhanced photocatalytic activity in the degradation of an MO dye solution by reducing the electron-hole pair recombination rate; the photogenerated electrons were trapped in $\mathrm{rGO}$, leading to the formation of reactive superoxide anions, and the photocatalytic activity varied depending on the rGO loading in the $\mathrm{SnO}_{2}$ aerogel matrix. This enhancement in photocatalytic activity with $\mathrm{rGO}$ addition in aerogel structure was due to the movement of photogenerated electrons to conduction band in rGO which reduces the recombination rate. In 60 min under UV irradiation, the pristine $\mathrm{SnO}_{2}$ aerogel and the $\mathrm{SnO}_{2}$ aerogel/rGO (0.1 wt. \%) nanocomposites achieved an $\mathrm{MO}$ degradation of $56 \%$ and $84 \%$ degradation, respectively. Therefore, $\mathrm{SnO}_{2}$ aerogel/rGO nanocomposites could be good candidates for the photodegradation of organic pollutants in industrial wastewater.

Author Contributions: Methodology, T.K. and H.-H.P.; investigation, T.K.; formal analysis, T.K., Y.K., H.-N.-R.J., Z.D., D.D., A.B., S.E., and V.G.P.; writing—original draft preparation, T.K.; writing-review and editing, V.G.P. and H.-H.P.

Funding: This work was supported by 'Korea-Africa Joint Research Programme' grant funded by the Korea government (Ministry of Science, Technology \& ICT) in 2017K1A3A1A09085891. This work was supported (researched) by the third Stage of Brain Korea 21 Plus Project in 2019.

Conflicts of Interest: The authors declare no conflict of interest.

\section{References}

1. Kim, S.P.; Choi, M.Y.; Choi, H.C. Characterization and photocatalytic performance of $\mathrm{SnO}_{2}-\mathrm{CNT}$ nanocomposites. Appl. Surf. Sci. 2015, 357, 302-308. [CrossRef]

2. Zhu, X.; An, S.; Liu, Y.; Hu, J.; Liu, H.; Tian, C.; Dai, S.; Yang, X.; Wang, H.; Abney, C.W.; et al. Efficient removal of organic dye pollutants using covalent organic frameworks. Aiche J. 2017, 63, 3470-3478. [CrossRef]

3. Sreekanth, T.V.M.; Shim, J.-J.; Lee, Y.R. Degradation of organic pollutants by bio-inspired rectangular and hexagonal titanium dioxide nanostructures. J. Photochem. Photobiol. B Biol. 2017, 169, 90-95. [CrossRef] [PubMed]

4. Wang, W.; Tadé, M.O.; Shao, Z. Research progress of perovskite materials in photocatalysis- and photovoltaics-related energy conversion and environmental treatment. Chem. Soc. Rev. 2015, 44, 5371-5408. [CrossRef] [PubMed]

5. Upadhyay, R.K.; Soin, N.; Roy, S.S. Role of graphene/metal oxide composites as photocatalysts, adsorbents and disinfectants in water treatment: A review. RSC Adv. 2014, 4, 3823-3851. [CrossRef]

6. Qin, C.; Li, Z.; Chen, G.; Zhao, Y.; Lin, T. Fabrication and visible-light photocatalytic behavior of perovskite praseodymium ferrite porous nanotubes. J. Power Sour. 2015, 285, 178-184. [CrossRef] 
7. Yang, Z.; Chen, S.; Fu, K.; Liu, X.; Li, F.; Du, Y.; Zhou, P.; Cheng, Z. Highly efficient adsorbent for organic dyes based on a temperature- and pH-responsive multiblock polymer. J. Appl. Polym. Sci. 2018, 135, 46626. [CrossRef]

8. Zucker, I.; Lester, Y.; Avisar, D.; Hübner, U.; Jekel, M.; Weinberger, Y.; Mamane, H. Influence of Wastewater Particles on Ozone Degradation of Trace Organic Contaminants. Environ. Sci. Technol. 2015, 49, 301-308. [CrossRef] [PubMed]

9. Lee, D.-S.; Lee, S.-Y.; Rhee, K.Y.; Park, S.-J. Effect of hydrothermal temperature on photocatalytic properties of $\mathrm{TiO}_{2}$ nanotubes. Curr. Appl. Phys. 2014, 14, 415-420. [CrossRef]

10. Pant, A.; Tanwar, R.; Kaur, B.; Mandal, U.K. A magnetically recyclable photocatalyst with commendable dye degradation activity at ambient conditions. Sci. Rep. 2018, 8, 14700. [CrossRef] [PubMed]

11. Wang, M.; You, M.; Zhang, K.; Zhang, Y.; Han, J.; Fu, R.; Liu, S.; Zhu, T. Bi $i_{3.64} \mathrm{Mo}_{0.36} \mathrm{O}_{6.55} / \mathrm{Bi}_{2} \mathrm{MoO}_{6}$ heterostructure composite with enhanced photocatalytic activity for organic pollutants degradation. J. Alloy. Compd. 2018, 766, 1037-1045. [CrossRef]

12. Zhang, Y.; Park, M.; Kim, H.-Y.; El-Newehy, M.; Rhee, K.Y.; Park, S.-J. Effect of $\mathrm{TiO}_{2}$ on photocatalytic activity of polyvinylpyrrolidone fabricated via electrospinning. Compos. Part B Eng. 2015, 80, 355-360. [CrossRef]

13. Wang, H.; Qiu, X.; Liu, W.; Yang, D. Facile preparation of well-combined lignin-based carbon/ZnO hybrid composite with excellent photocatalytic activity. Appl. Surf. Sci. 2017, 426, 206-216. [CrossRef]

14. Anjum, M.; Miandad, R.; Waqas, M.; Gehany, F.; Barakat, M.A. Remediation of wastewater using various nano-materials. Arab. J. Chem. 2016. [CrossRef]

15. Karri, R.R.; Tanzifi, M.; Tavakkoli Yaraki, M.; Sahu, J.N. Optimization and modeling of methyl orange adsorption onto polyaniline nano-adsorbent through response surface methodology and differential evolution embedded neural network. J. Environ. Manag. 2018, 223, 517-529. [CrossRef] [PubMed]

16. Pastrana-Martínez, L.M.; Morales-Torres, S.; Likodimos, V.; Figueiredo, J.L.; Faria, J.L.; Falaras, P.; Silva, A.M.T. Advanced nanostructured photocatalysts based on reduced graphene oxide- $\mathrm{TiO}_{2}$ composites for degradation of diphenhydramine pharmaceutical and methyl orange dye. Appl. Catal. B Environ. 2012, 123-124, 241-256. [CrossRef]

17. Khalid, N.R.; Ahmed, E.; Hong, Z.; Zhang, Y.; Ullah, M.; Ahmed, M. Graphene modified $\mathrm{Nd} / \mathrm{TiO}_{2}$ photocatalyst for methyl orange degradation under visible light irradiation. Ceram. Int. 2013, 39, 3569-3575. [CrossRef]

18. Filice, S.; D'Angelo, D.; Libertino, S.; Nicotera, I.; Kosma, V.; Privitera, V.; Scalese, S. Graphene oxide and titania hybrid Nafion membranes for efficient removal of methyl orange dye from water. Carbon 2015, 82, 489-499. [CrossRef]

19. Bhattacharjee, A.; Ahmaruzzaman, M.; Sinha, T. A novel approach for the synthesis of $\mathrm{SnO}_{2}$ nanoparticles and its application as a catalyst in the reduction and photodegradation of organic compounds. Spectrochim. Acta Part A Mol. Biomol. Spectrosc. 2015, 136, 751-760. [CrossRef] [PubMed]

20. Kumar, M.; Mehta, A.; Mishra, A.; Singh, J.; Rawat, M.; Basu, S. Biosynthesis of tin oxide nanoparticles using Psidium Guajava leave extract for photocatalytic dye degradation under sunlight. Mater. Lett. 2018, 215, 121-124. [CrossRef]

21. Zhu, L.-P.; Bing, N.-C.; Yang, D.-D.; Yang, Y.; Liao, G.-H.; Wang, L.-J. Synthesis and photocatalytic properties of core-shell structured $\alpha-\mathrm{Fe}_{2} \mathrm{O}_{3} @ \mathrm{SnO}_{2}$ shuttle-like nanocomposites. Cryst. Eng. Comm. 2011, 13, 4486-4490. [CrossRef]

22. Oh, T. Effect of double junctions in nano structure oxide materials and gas sensitivity. Trans. Electr. Electron. Mater. 2018, 19, 382-386. [CrossRef]

23. Wang, N.; Xu, J.; Guan, L. Synthesis and enhanced photocatalytic activity of tin oxide nanoparticles coated on multi-walled carbon nanotube. Mater. Res. Bull. 2011, 46, 1372-1376. [CrossRef]

24. Wang, C.; Wang, X.; Xu, B.-Q.; Zhao, J.; Mai, B.; Peng, P.; Sheng, G.; Fu, J. Enhanced photocatalytic performance of nanosized coupled $\mathrm{ZnO} / \mathrm{SnO}_{2}$ photocatalysts for methyl orange degradation. J. Photochem. Photobiol. A Chem. 2014, 168, 47-52. [CrossRef]

25. Li, Y.; Li, X.; Li, J.; Yin, J. Photocatalytic degradation of methyl orange by $\mathrm{TiO}_{2}$-coated activated carbon and kinetic study. Water Res. 2006, 40, 1119-1126. [CrossRef] [PubMed]

26. Tian, C.; Zhang, Q.; Wu, A.; Jiang, M.; Liang, Z.; Jiang, B.; Fu, H. Cost-effective large-scale synthesis of ZnO photocatalyst with excellent performance for dye photodegradation. Chem. Commun. 2012, 48, 2858-2860. [CrossRef] [PubMed] 
27. Jiwan, S.; Prasanna, L.L.; Yoon-Young, C.; Jae-Kyu, Y.; Reddy, K.J. Degradation and mechanism of methyl orange by nanometallic particles under a fenton-like process. Environ. Eng. Sci. 2017, 34, 350-356. [CrossRef]

28. Singh, J.; Chang, Y.-Y.; Koduru, J.R.; Yang, J.-K.; Singh, D.P. Rapid Fenton-like degradation of methyl orange by ultrasonically dispersed nano-metallic particles. Environ. Eng. Res. 2017, 22, 245-254. [CrossRef]

29. Tammina, S.K.; Mandal, B.K.; Kadiyala, N.K. Photocatalytic degradation of methylene blue dye by nonconventional synthesized $\mathrm{SnO}_{2}$ nanoparticles. Environ. Nanotechnol. Monit. Manag. 2018, 10, 339-350. [CrossRef]

30. Dai, S.; Yao, Z. Synthesis of flower-like $\mathrm{SnO}_{2}$ single crystals and its enhanced photocatalytic activity. Appl. Surf. Sci. 2012, 258, 5703-5706. [CrossRef]

31. Pal, M.; Bera, S.; Jana, S. Sol-gel based simonkolleite nanopetals with $\mathrm{SnO}_{2}$ nanoparticles in graphite-like amorphous carbon as an efficient and reusable photocatalyst. RSC Adv. 2015, 5, 75062-75074. [CrossRef]

32. Hejazi Juybari, S.A.; Milani Moghaddam, H. Facile fabrication of porous hierarchical $\mathrm{SnO}_{2}$ via a self-degraded template and their remarkable photocatalytic performance. Appl. Surf. Sci. 2018, 457, 179-186. [CrossRef]

33. Dhanalakshmi, M.; Saravanakumar, K.; Lakshmi Prabavathi, S.; Abinaya, M.; Muthuraj, V. Fabrication of novel surface plasmon resonance induced visible light driven iridium decorated $\mathrm{SnO}_{2}$ nanorods for degradation of organic contaminants. J. Alloys. Compd. 2018. [CrossRef]

34. Zhang, P.; Wang, L.; Zhang, X.; Shao, C.; Hu, J.; Shao, G. $\mathrm{SnO}_{2}$-core carbon-shell composite nanotubes with enhanced photocurrent and photocatalytic performance. Appl. Catal. B Environ. 2015, 166-167, 193-201. [CrossRef]

35. Liang, Y.; Wu, W.; Wang, P.; Liou, S.-C.; Liu, D.; Ehrman, S.H. Scalable fabrication of $\mathrm{SnO}_{2} / \mathrm{eo}^{-\mathrm{GO}}$ nanocomposites for the photoreduction of $\mathrm{CO}_{2}$ to $\mathrm{CH}_{4}$. Nano Res. 2018, 11, 4049-4061. [CrossRef]

36. Begum, S.; Ahmaruzzaman, M. Biogenic synthesis of $\mathrm{SnO}_{2}$ /activated carbon nanocomposite and its application as photocatalyst in the degradation of naproxen. Appl. Surf. Sci. 2018, 449, 780-789. [CrossRef]

37. Ding, S.-S.; Huang, W.-Q.; Zhou, B.-X.; Peng, P.; Hu, W.-Y.; Long, M.-Q.; Huang, G.-F. The mechanism of enhanced photocatalytic activity of $\mathrm{SnO}_{2}$ through fullerene modification. Curr. Appl. Phys. 2017, 17, 1547-1556. [CrossRef]

38. Hung-Low, F.; Ramirez, D.A.; Peterson, G.R.; Hikal, W.M.; Hope-Weeks, L.J. Development of a carbon-supported $\mathrm{Sn}-\mathrm{SnO}_{2}$ photocatalyst by a new hybridized sol-gel/dextran approach. RSC Adv. 2016, 6, 21019-21025. [CrossRef]

39. Chen, Y.; Li, H.; Ma, Q.; Zhang, Z.; Wang, J.; Wang, G.; Che, Q.; Yang, P. A novel electrospun approach for highly-dispersed carambola-like $\mathrm{SnO}_{2} / \mathrm{C}$ composite microparticles with superior photocatalytic performance. Mater. Lett. 2017, 202, 17-20. [CrossRef]

40. Mahadik, D.B.; Lee, Y.K.; Park, C.-S.; Chung, H.-Y.; Hong, M.-H.; Jung, H.-N.-R.; Han, W.; Park, H.-H. Effect of water ethanol solvents mixture on textural and gas sensing properties of tin oxide prepared using epoxide-assisted sol-gel process and dried at ambient pressure. Solid State Sci. 2015, 50, 1-8. [CrossRef]

41. Jung, H.-N.-R.; Parale, V.G.; Kim, T.; Cho, H.H.; Park, H.-H. Zirconia-based alumina compound aerogels with enhanced mesopore structure. Ceram. Int. 2018, 44, 10579-10584. [CrossRef]

42. Parale, V.G.; Jung, H.-N.-R.; Han, W.; Lee, K.-Y.; Mahadik, D.B.; Cho, H.H.; Park, H.-H. Improvement in the high temperature thermal insulation performance of $\mathrm{Y}_{2} \mathrm{O}_{3}$ opacified silica aerogels. J. Alloy. Compd. 2017, 727, 871-878. [CrossRef]

43. Huang, R.; Hou, L.; Zhou, B.; Zhao, Q.; Ren, S. Formation and characterization of tin oxide aerogel derived from sol-gel process based on Tetra(n-butoxy)tin(IV). J. Non-Cryst. Solids 2005, 351, 23-28. [CrossRef]

44. Zhao, Z.; Chen, D.; Jiao, X. Zirconia aerogels with high surface area derived from sols prepared by electrolyzing zirconium oxychloride solution: Comparison of aerogels prepared by freeze-drying and supercritical $\mathrm{CO}_{2}$ (I) Extraction. J. Phys. Chem. C 2007, 777, 18738-18743. [CrossRef]

45. Kido, Y.; Nakanishi, K.; Miyasaka, A.; Kanamori, K. Synthesis of monolithic hierarchically porous iron-based xerogels from Iron(III) salts via an epoxide-mediated sol-gel process. Chem. Mater. 2012, 24, 2071-2077. [CrossRef]

46. Baumann, T.F.; Kucheyev, S.O.; Gash, A.E.; Satcher, J.H. Facile synthesis of a crystalline, high-surface-area $\mathrm{SnO}_{2}$ aerogel. Adv. Mater. 2005, 17, 1546-1548. [CrossRef]

47. Rakibuddin, M.; Ananthakrishnan, R. A novel Ag deposited nanocoordination polymer derived porous $\mathrm{SnO}_{2} / \mathrm{NiO}$ heteronanostructure for the enhanced photocatalytic reduction of $\mathrm{Cr}(\mathrm{VI})$ under visible light. New J. Chem. 2016, 40, 3385-3394. [CrossRef] 
48. Wang, Z.-1.; Xu, D.; Huang, Y.; Wu, Z.; Wang, L.-m.; Zhang, X.-B. Facile, mild and fast thermal-decomposition reduction of graphene oxide in air and its application in high-performance lithium batteries. Chem. Commun. 2012, 48, 976-978. [CrossRef] [PubMed]

49. Da Cunha, C.R.; Toffolo, G.H.; dos Santos, C.E.I.; Pezzi, R.P. Structural, optical and chemical characterizations of sol-gel grown tin oxide aerogels. J. Non-Cryst. Solids 2013, 380, 48-52. [CrossRef]

50. Zhang, H.; Lv, X.; Li, Y.; Wang, Y.; Li, J. P25-Graphene composite as a high performance photocatalyst. ACS Nano 2010, 4, 380-386. [CrossRef] [PubMed]

51. Wan, F.; Lü, H.-Y.; Wu, X.-L.; Yan, X.; Guo, J.-Z.; Zhang, J.-P.; Wang, G.; Han, D.-X.; Niu, L. Do the bridging oxygen bonds between active $\mathrm{Sn}$ nanodots and graphene improve the Li-storage properties? Energy Storage Mater. 2016, 5, 214-222. [CrossRef]

52. Chen, F.-J.; Cao, Y.-L.; Jia, D.-Z. A room-temperature solid-state route for the synthesis of graphene oxide-metal sulfide composites with excellent photocatalytic activity. Cryst. Eng. Comm. 2013, 15, 4747-4754. [CrossRef]

53. Wang, C.; Shao, C.; Zhang, X.; $\mathrm{Liu}, \mathrm{Y} . \mathrm{SnO}_{2}$ nanostructures- $\mathrm{TiO}_{2}$ nanofibers heterostructures: Controlled fabrication and high photocatalytic properties. Inorg. Chem. 2009, 48, 7261-7268. [CrossRef] [PubMed]

54. Wang, P.; Zhan, S.; Xia, Y.; Ma, S.; Zhou, Q.; Li, Y. The fundamental role and mechanism of reduced graphene oxide in $\mathrm{rGO} / \mathrm{Pt}-\mathrm{TiO}_{2}$ nanocomposite for high-performance photocatalytic water splitting. Appl. Catal. B Environ. 2017, 207, 335-346. [CrossRef]

55. Cao, Y.; Li, Y.; Jia, D.; Xie, J. Solid-state synthesis of $\mathrm{SnO}_{2}-$ Graphene nanocomposite for photocatalysis and formaldehyde gas sensing. RSC Adv. 2014, 4, 46179-46186. [CrossRef]

56. Zhu, Y.; Wang, Y.; Yao, W.; Zong, R.; Zhu, Y. New insights into the relationship between photocatalytic activity and $\mathrm{TiO}_{2}-\mathrm{GR}$ composites. RSC Adv. 2015, 5, 29201-29208. [CrossRef]

57. Yadav, H.M.; Kim, J.-S. Solvothermal synthesis of anatase $\mathrm{TiO}_{2}-$ Graphene oxide nanocomposites and their photocatalytic performance. J. Alloy. Compd. 2016, 688, 123-129. [CrossRef]

58. Jo, W.-K.; Won, Y.; Hwang, I.; Tayade, R.J. Enhanced photocatalytic degradation of aqueous nitrobenzene using graphitic carbon- $\mathrm{TiO}_{2}$ composites. Ind. Eng. Chem. Res. 2014, 53, 3455-3461. [CrossRef]

(C) 2019 by the authors. Licensee MDPI, Basel, Switzerland. This article is an open access article distributed under the terms and conditions of the Creative Commons Attribution (CC BY) license (http:/ / creativecommons.org/licenses/by/4.0/). 